British Journal of Psychology (2003), 94, 55I-56I

(c) 2003 The British Psychological Society

\title{
Intelligence and class mobility in the British population
}

\author{
Daniel Nettle*
}

Departments of Psychology and Biological Sciences, The Open University, UK

\begin{abstract}
Performance on intelligence tests is known to be associated with class mobility, with high scorers tending to move up the socio-economic hierarchy, and low scorers tending to move down. However, much remains unknown about the association. It is possible that the importance of intelligence varies across different occupational areas, or that there is friction acting against mobility, such that a person from an underprivileged background would have to be more intelligent in order to reach a given position than someone who had had greater social advantage. Data from a longitudinal study of a broad, socially representative cohort of the British population (the NCDS) are used to investigate these questions. The results show that intelligence test scores in childhood are associated with class mobility in adulthood uniformly across all social classes. There is no evidence that those from underprivileged backgrounds have to be disproportionately able in order to reach the professional classes. The study reveals an apparently high level of social mobility and meritocracy in contemporary Britain.
\end{abstract}

The scores adults achieve on intelligence tests are correlated with their socio-economic status (Herrnstein \& Murray, 1994; Mascie-Taylor \& Gibson, 1978; McCall, 1977; Murnane, Willett \& Levy, 1995; Tittle \& Rotolo, 2000; Waller, 1971). The causality could run in either direction, or both. On the one hand, parental social class is related to offspring IQ scores (Bouchard \& Segal, 1985; Mascie-Taylor, 1984). Adoption studies consistently find a small but non-zero effect of the home environment on the development of intelligence (Capron \& Duyme, 1989; Dumaret \& Stewart, 1985; Horn, Loehlin \& Willerman, 1979; Scarr \& Weinberg, 1977), though, it should be noted, this effect appears to decline with age, just as estimates of heritability of IQ increase with age. Thus it can be argued that some of the correlation between social class and intelligence comes about through the socio-economic circumstances of childhood affecting the development of intelligence.

On the other hand, intelligence can affect socio-economic status. Intelligence test

\footnotetext{
* Requests for reprints should be addressed to Dr Daniel Nettle, Departments of Psychology and Biological Sciences, The Open University, Watton Hall, Milton Keynes, MK7 6AA, UK (e-mail: d.nettle@open.ac.uk).
} 
scores predict movement from the parental social class to a higher or lower one (Jencks, 1972; Mascie-Taylor \& Gibson, 1978; Waller, 1971). The association between social class as an adult and IQ is stronger than that between social class at birth and IQ. Thus intelligence is causally involved with processes of social mobility that match people's occupations with their aptitudes. Part of this is mediated through educational attainment. IQ scores are the best single predictors of educational performance (McCall, 1977), and achieved education is a major determinant of occupational class. However, there is also evidence for a separate effect due, presumably, to the influence of intelligence on performance in the workplace itself (Jencks, 1972; Waller, 1971).

Studies of intelligence and class mobility have been much rarer than those of static social class and intelligence, since they necessarily require a longitudinal aspect. Two previous studies (Mascie-Taylor \& Gibson, 1978; Waller, 1971) have demonstrated that men who are upwardly mobile in socio-economic terms tend to have higher IQ scores than their fathers, whilst those who are downwardly mobile tend to have lower scores. Mascie-Taylor and Gibson's study further suggests that the degree of mobility is linearly related to the difference between the son's and father's scores. However, the sample size was relatively small ( 85 father-son pairs). This meant that the number of participants for each degree of mobility was relatively small (with six men moving up three places on a 5-point scale, and only one man moving down three places). The standard errors on Mascie-Taylor and Gibson's associations are thus very large, and the studies leave a number of questions about the detail of the relationship between intelligence and class mobility unanswered. First, it is not clear how strong the IQ-class mobility effect is across the broad spectrum of society. How much of the variation in class mobility is related to IQ, how much is due to other individual difference or random factors, and how much is the result of social inertia?

Second, IQ score might facilitate class mobility to different extents depending on whereabouts on the scale one is moving to. For example, it might be argued that a move from manual work to a profession with academic entry qualifications would require a relatively high IQ score, whereas a move from routine unskilled work to skilled manual work would not. Under the usual definitions of occupational class, these two transitions would be of equal step size, but their associations with intelligence could be quite different.

Third, there may be friction acting against mobility. The Robbins report into university education in Britain (Robbins, 1963) famously showed that the IQ a working-class person needed in order to get to university was higher than that needed by someone with a more privileged background. A similar effect could apply to occupational class. A person from a disadvantaged socio-economic stratum might have to be more intelligent to reach a certain profession than someone starting from a more privileged position. This would be due to differential access to good educational institutions, informal networks of knowledge and assistance, and other forms of social advantage.

The purpose of this paper is to examine the relationship between social mobility and IQ scores in the British population with these three factors-the strength of the relationship, the uniformity of the relationship across the classes, and the existence of friction effects - in mind. The research question demands a very large and socially representative sample, since it is necessary to have all possible social classes of origins and attained social classes represented in sufficient number. For this reason, the data of the National Child Development Study (NCDS) have been used. The NCDS cohort consists of all the children born in the UK in a particular week in March 1958, and is thus 
representative by design of the whole British population. The data set is many times larger than that of Mascie-Taylor and Gibson (1978), and has it has been shown elsewhere that the size and broad base allow very subtle relationships to be detected (Leask \& Crow, 2001; Nettle, 2002).

The relationship between intelligence test scores and social class in this data set has been examined before (Mascie-Taylor, 1984). However, at that time the cohort were children, and thus their own class trajectory was not yet clear, so the analysis could not be extended to class mobility.

\section{Methods}

The data are from Britain's National Child Development Study (NCDS). This is an ongoing longitudinal investigation of all the children born in Britain between 3 and 9 March 1958. It is intended to be a complete sample of a time slice of the British population. The original perinatal survey (Butler \& Bonham, 1963) has been followed up with six mainly questionnaire-based 'sweeps' of the cohort, which taken together provide a mine of medical, educational and sociological information (Ferri, 1993; Fogelman, 1983). The most recent sweep was in 2000, at the cohort age of 42 years (Bynner, Butler, Ferri, Shepherd \& Smith, 2001). The initial size of the NCDS cohort was 17,414 boys and girls. Many individuals have been lost to follow-up over the years, through emigration, death, movement with no forwarding address, or non-cooperation with the study. The number successfully contacted in 1991 was 11,407 , and in 2000 was 11,419 , though not all of these individuals have complete records. The present study uses only those with complete records for all the relevant variables.

Loss to follow-up in the cohort is not randomly distributed. The lower social classes at birth have higher rates of loss to follow-up (class I: $35.7 \%$; class II: $32.5 \%$; class III $37.4 \%$; class IV 37.3\%; class V 44.1\%; overall association $\chi^{2}=53.15, d f=4, p<.001$ ). Those lost to follow-up between the ages of 11 and 42 also have lower General Ability scores than those who remained in the study (means 39.27 vs. $44.56 ; t=18.16$, $d f=14,133, p<.001)$. However, it is not felt that this association confounds the results presented here, since these are based not on frequencies of occurrence, but on scores. Moreover, for all social classes, it remains the case that the majority of individuals have complete records, and all cells of both class of origin and class attained are populated with a significant-sized sample.

This paper presents results only for the men in the cohort. Class mobility is assessed by comparing the occupational class of the cohort member with that of his father. The women have been excluded because of the difficulty in assessing class mobility in their case. The study provides information on the social class of the father or male head of household at the time of the cohort member's birth. Whilst there is some information on maternal employment, many of the mothers did not work. Comparing the women's present occupational class with that of their mothers would be confounded by the great changes in labour force participation amongst women in the last few decades. Comparing women's present occupational class with that of their fathers would not be strictly valid, as it would simply reflect sex differences in occupational structure. Furthermore, occupational class measures are less useful as classifiers of socio-economic status for women of child-bearing age than they are for men, since many women with children work part-time or move to the margins of the labour force. They are then assigned to an occupational class that may not reflect their true socio-economic position. 
The cohort members were tested at age 11 years using the General Ability test (Douglas, 1964). This is an IQ-type test with verbal and non-verbal subscales (for detailed description of the tests and the distribution of results, see Leask and Crow (2001) and Mascie-Taylor (1984)). The two subscale scores are also combined to give a general ability (GA) score. The two subscales are highly correlated (for the men, $r=.80$, $d f=4,844, p<.001)$, and none of the results presented here, which use the combined GA score, is materially affected by using either of the subcomponents instead.

The cohort members' own social class in adulthood (attained social class) was determined from occupation in 2000. By this time, at age 42 years, the cohort would have established their likely career trajectories clearly. The classification used (Table 1) represents the five classes of the Registrar General's class classification (Leete \& Fox, 1977; OPCS, 1980). This classification was originally devised to reflect the 'standing in the community' of different types of occupation, although it was subsequently reconceived in terms of more objective correlates of socio-economic position. It is not just a typology but an ordinal classification, so that class $I$ is designed to reflect a higher socio-economic status than class II, and so on.

Paternal social class was coded from father's occupation at several points, using the same classification. The two variables considered for use here were father's social class at the time of cohort member's birth (1958), and that at cohort member age 11 (1969). The former has the advantage of the largest complete sample size $(N=5,088)$. The latter has a slightly smaller sample size $(N=4,529)$. However, the fathers can be assumed to have been closer in age in 1969 to the cohort members themselves in 2000. Thus, by using the 1969 variable, one is measuring the men and their fathers at similar points in their careers. This assumption is supported by the fact that the correlation between attained and paternal social class is higher considering paternal class from 1969 than from $1958(r=.26, d f=4,080, p<.001$ vs. $r=.23, d f=4,576, p<.001)$ and the mean difference between attained social class and paternal class in 1969 is smaller than that between attained social class and paternal class in 1958 (.36 vs. .44). Having said this, there is a high degree of consistency between the paternal class variables at the two time points, with $57.7 \%$ of the fathers remaining in the same class, and a correlation between the two variables of $.55(d f=4,201, p<.001)$. Henceforth the 1969 variable is used as the paternal social class.

Subtracting the attained social class from the paternal social class gives a measure of class trajectory, which is zero if the class has stayed the same, positive if the person has moved up the socio-economic scale, and negative if they have moved down.

\section{Results}

The distribution of men into classes is given in Table 1 . The distributions are different for the men themselves than for their fathers. The fathers' distribution is dominated by social class III, which accounts for $52.1 \%$ of individuals. By contrast, class III contains only $37.3 \%$ of the men themselves. This change is explained mainly by an approximate doubling of the proportion of men in classes I and II over the intervening years. This change in occupational structure can be quantified by considering the class mobility variable, which is father's social class minus offspring social class. This variable has a mean of $0.36(S D=1.07)$. This differs from 0 at $p<.001$. Thus there is a secular trend towards the higher occupational groups.

The correlation between men's attained and paternal social class is $.26(d f=4,080$, 
Table I. The five classes of the Registrar General's classification, along with the breakdown of the sample in terms of paternal social class (1969) and own attained social class (2000)

\begin{tabular}{llrr}
\hline Class & \multicolumn{1}{c}{ Description } & Paternal & Own \\
\hline & & 299 & 375 \\
I & Professional occupations & 855 & 2,009 \\
II & Managerial and technical occupations & 2,358 & 2,100 \\
III & Skilled occupations (manual and non-manual) & 755 & 426 \\
IV & Partly-skilled occupations & 262 & 128 \\
V & Unskilled occupations & 4,529 & 5,038 \\
& Total & & \\
\hline
\end{tabular}

Note. The subdivision of class III into manual and non-manual is not used in this study.

$p<.001)$. This indicates some inter-generational transmission of class, but also considerable mobility. The frequency distribution of class trajectory (Fig. 1) shows that, for the men, $39.5 \%$ of individuals are in the same class as their father, and $29.6 \%$ have gone up by one class. Much of this movement represents not so much individual social mobility as the general change in occupational structure of the British economy. However, 17.1\% of men have moved two or more classes in either direction, and this does represent genuine social mobility. The correlation of .26 means that just $7 \%$ of the variation in attained social class is associated with paternal class. The amount of variation caused by

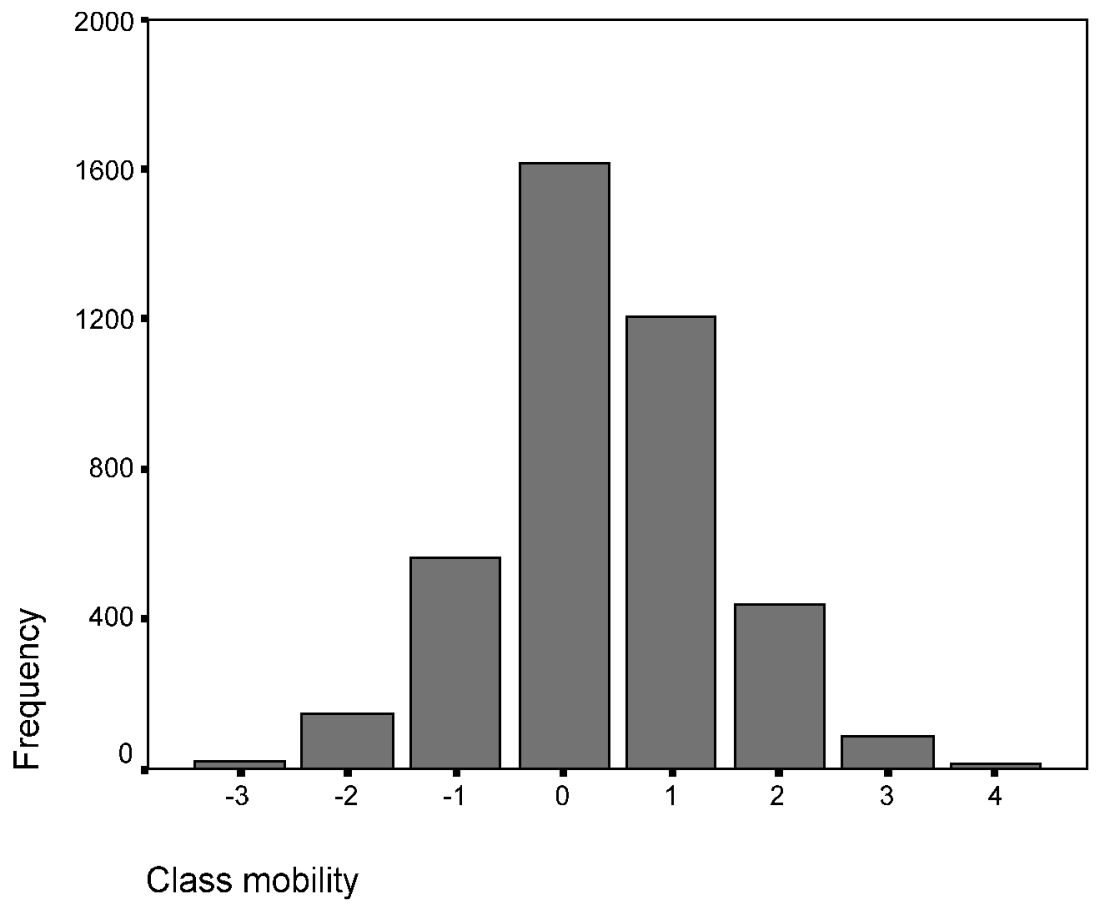

Figure I. The distribution of class trajectory (paternal minus attained social class). 


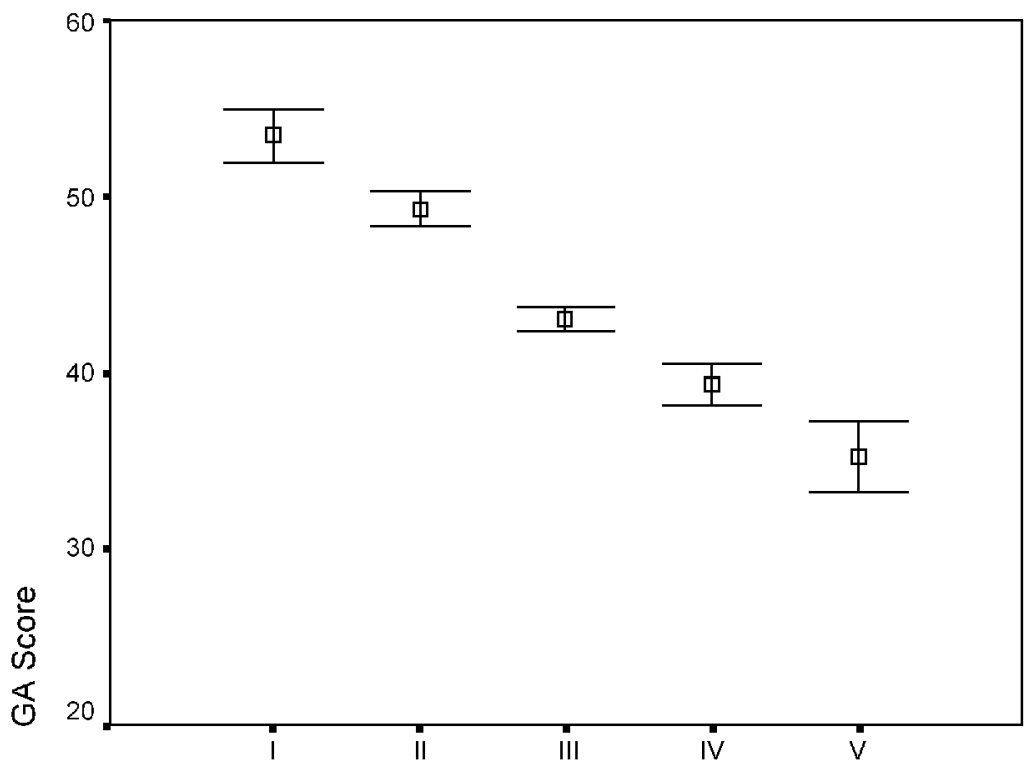

Paternal Social Class

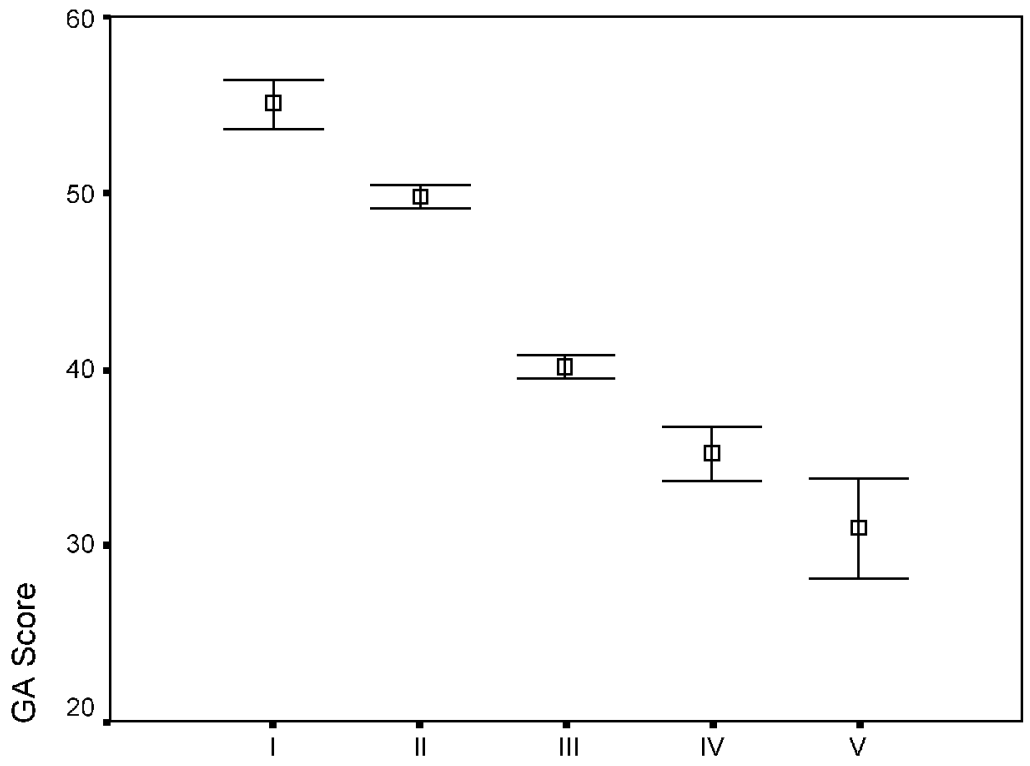

Attained Social Class

Figure 2. General ability scores (mean and $95 \%$ confidence interval for mean) by paternal social class (top) and attained social class (bottom). 
paternal class is likely to be significantly lower, since one reason for parent and offspring social classes to be similar is similar intrinsic aptitudes. The partial correlation between paternal social class and attained social class controlling for GA score is only $.16(d f=3,819, p<.001)$.

As has been reported elsewhere (Mascie-Taylor 1984), there is an association between GA score and paternal class $(r=-.28, d f=4,286, p<.001)$. The difference between classes $\mathrm{I}$ and $\mathrm{V}$ is around 15 points, or one standard deviation. The relationship between attained social class at age 42 and GA score at age 11 is stronger than that between paternal social class and GA score $(r=-0.39, d f=4,353, p<.001$; difference between the correlations is significant at $p<.001)$. For attained social class, the difference in means between classes $\mathrm{I}$ and $\mathrm{V}$ is 24.1 points, or 1.55 standard deviations. Thus, as other studies have also found, attained social class in adulthood is more strongly related to GA score than parental social class is (Fig. 2).

It is statistically problematic to search for a general correlation between GA score and class mobility. A person born into class I can only go down or stay the same; a person born into class $\mathrm{V}$ can only go up or stay the same. Thus the distribution and range are very different across the sample. What can be done is to compare men with the same paternal class and different GA scores.

The correlations between GA score and class trajectory were computed within each paternal social class. As Table 2 shows, these are all highly significant and all positive. The weighted mean of the correlations in Table 2 is .35 . Thus $13 \%$ of the variation in class mobility is associated with GA scores. The correlations do not differ significantly from each other. Thus, there do not appear to be any differences in the slope or direction of the relationship of class mobility to GA score across the different paternal social classes. Wherever on the scale the men are born, the higher the GA score, the more positive the mobility.

Table 2. Correlations between men's GA score and class trajectory, broken down by paternal social class

\begin{tabular}{lrr}
\hline Paternal class & $r$ & \multicolumn{1}{c}{$d f$} \\
\hline I & .31 & 255 \\
II & .33 & 744 \\
III & .37 & 2,010 \\
IV & .32 & 612 \\
V & .39 & 196 \\
\hline
\end{tabular}

Note. All correlations are significant at $p<.001$, but they do not differ significantly from each other.

The relationships are shown graphically in Fig. 3. The curves all increase uniformly, and are all of similar slope. Thus it seems that increasing intelligence increases occupational success uniformly regardless of where in the social distribution an individual starts or finishes. (Note that, in Fig. 3, even the highest GA scorers in class I were downwardly mobile on average. This is because there was only one direction for them to move in.) 


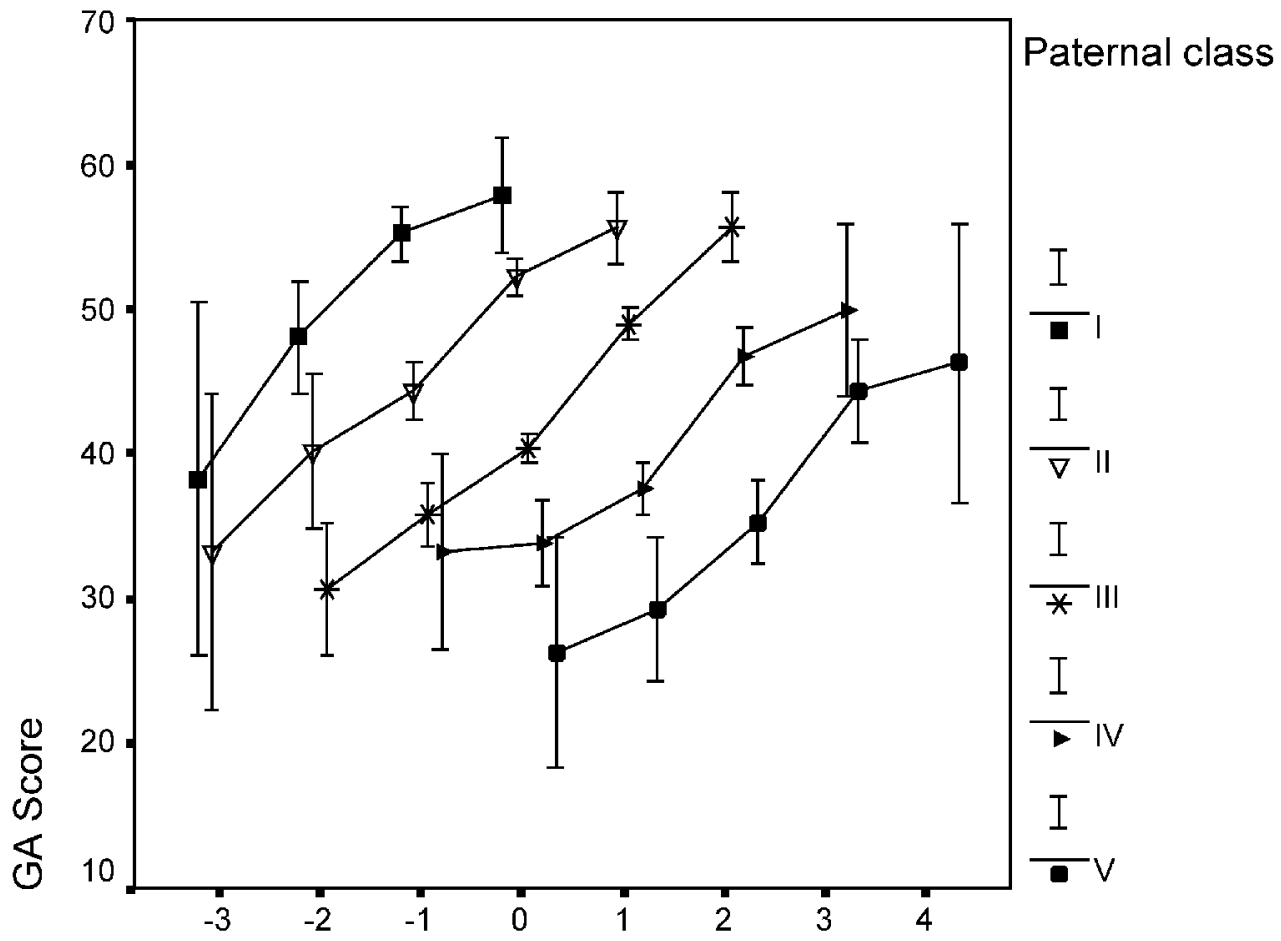

\section{Class Trajectory}

Figure 3. Mean General Ability score for men with different class trajectories, broken down by paternal social class.

If the mean GA score of a man now in class I but born into class $\mathrm{V}$ were higher than the mean score of a man now in class I and born into that class, this would indicate a 'Robbins' effect, where there was friction on social mobility. That is, the level of ability required for the man of non-professional origin to reach the professional class would be greater than that required of a man who already had the background and connections to stay there. To test this possibility, mean GA scores for members of different attained classes were compared by class of origin. Figure 4 is a graphical representation of the analysis. There is no tendency for men who have moved up into the higher occupational classes to have higher scores than those who have reached them by staying put or moving down. In fact, the opposite is the case. Within attained classes I-IV, men from a high paternal class have significantly higher GA scores than those coming from a lower class (class I: $F(4,277)=2.91, p<.05$; class II: $F(4,1537)=14.23, p<0.001$; class III: $F(4,1590)=13.62, p<.001$; class IV: $F(4,311)=2.61, p<.05)$. Within attained class $\mathrm{V}$, the differences in GA scores between different paternal classes are not significant $(F(3,83)=0.62$, n.s. $)$.

\section{Discussion}

The data show clearly that general ability, an IQ-like score, is indeed a predictor of class mobility. Those reaching the professional class had a GA score about one and a half 


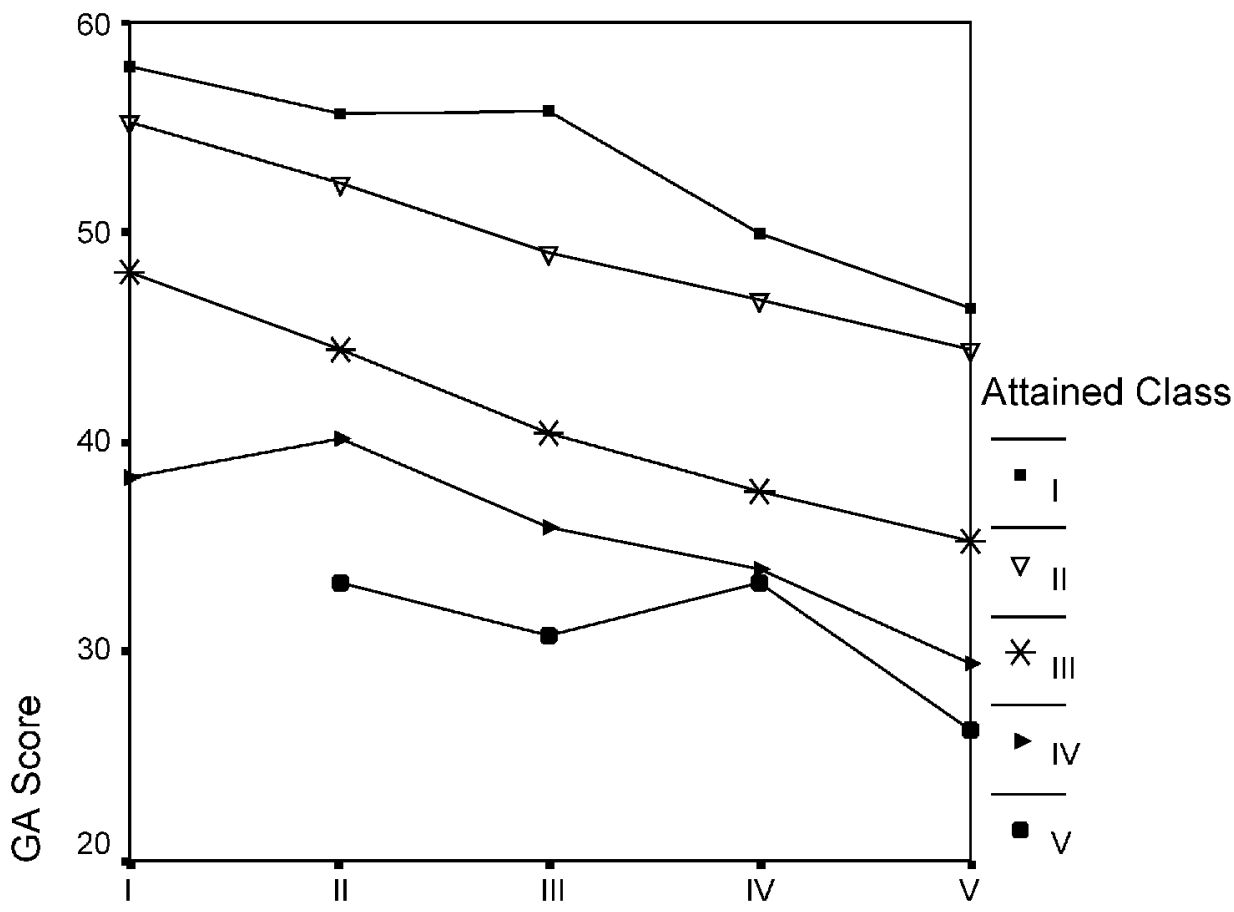

\section{Paternal Class}

Figure 4. General Ability score means for men in the different social classes, broken down by paternal social class.

standard deviations higher than those reaching the unskilled class, regardless of their class of origin. This finding accords with those of other studies (Jencks, 1972; MascieTaylor \& Gibson, 1978; Waller, 1971). Intellectual ability most probably has its causal effects through both educational attainment (McCall, 1977) and performance in the workplace itself (Hunter \& Hunter, 1984; Schmidt \& Ones, 1992). The effect of intelligence on class mobility appears to be uniform across the whole range of classes of origin and across the whole range of attained classes.

There is no evidence of a 'Robbins effect' on class mobility. Those entering the professional class from lower social strata do not have higher GA scores than those from more privileged backgrounds. In fact the opposite is the case; within four of the five classes, those from more privileged social backgrounds had higher GA scores than those from less privileged ones. The most likely explanation for this is that within the broad occupational groups, those from more privileged backgrounds are tending to occupy the highest level and most difficult to enter positions, which would tend to be related to the higher GA levels.

In all, these results suggest a more meritocratic and socially fluid picture of the British population than might have been expected. The relationship of parental social class to attained social class was weak ( $6 \%$ of the variation). Most of this was mediated through General Ability. Partialling out GA differences left only 3\% of the variation to be explained by direct effects of paternal class on occupational opportunities. This is a surprising finding, in view of the general perception that in Britain, as in other 
developed economies, an informal network of opportunities emerges around people and institutions that you know or that your parents know. This familiarity effect is clearly not overwhelmingly strong. The evidence is consistent with, even suggestive of, the possibility that within a broad occupational class, those from more privileged backgrounds tend to occupy the higher-level positions, but entry to the broad classes themselves seems to be widely attainable.

Scores on an intelligence test at age 11 are a significant determinant of people's occupational class at age 42 . It could be argued that at least part of this is causally trivial; since professions, firms and educational institutions increasingly use IQ-type tests to control entry (Tittle \& Rotolo, 2000), then those who are good at such tests are more likely to succeed in these spheres. However, if this was the only reason for the association between class mobility and IQ, it is unlikely that the association would be so uniform across all social classes, given that different occupational classes require academic qualifications and formal testing to radically differing extents. It is more likely that the GA score represents a genuine measure of aptitude across a broad range of situations.

This is in accordance with the increasingly accepted view that IQ tests have a widespread operational validity, even if the underlying cognitive mechanisms are not fully understood (Mackintosh, 1998). The association with attainment is not an artifact caused by IQ scores being a simple function of parental class. Indeed, the relationship between parental class and test score is much too weak (less than $5 \%$ of the variation) to justify the oft-stated critique that IQ testing amounts to a regressive reification of existing social privilege. The present data suggest that IQ scores are, as they were designed to be, a relatively class-neutral measure of aptitude. Of course, the significance of the findings should not be overstated. The vast majority of variation in both attained class and class mobility is not accounted for by IQ. Numerous other individual differences factors, including personality characteristics, values and health, as well as contingent events, have a strong role. IQ is only an imperfect measure of underlying biological and cognitive traits (Steele \& Aronson, 1995). Nonetheless, intelligence is the strongest single factor causing class mobility in contemporary societies that has been identified.

\section{References}

Bouchard, T. J., \& Segal, N. L. (1985). Environment and IQ. In B. B. Wolman (Ed.), Handbook of intelligence: Theories, methods and applications (pp. 391-464). New York: Wiley.

Butler, N. R., \& Bonham, D. G. (1963). Perinatal mortality. Edinburgh: E\&S Livingstone.

Bynner, J., Butler, N. R., Ferri, E., Shepherd, P., \& Smith, K. (2001). The design and conduct of the 1999-2000 surveys of the National Child Development Study and the 1970 British Cobort Study. London: Institute of Education, Centre for Longditudinal Studies.

Capron, C., \& Duyme, M. (1989). Assessment of effects of socioeconomic status on IQ in a full cross-fostering design. Nature, 340, 552-553.

Douglas, J. W. B. (1964). The home and the school. London: McGibbon and Kee.

Dumaret, A., \& Stewart, J. T. (1985). IQ, scholastic performance and behaviour of sibs raised in contrasting environments. Journal of Child Psychology and Psychiatry, 26, 553-580.

Ferri, E. (1993). Life at 33: The fifth follow-up of the National Child Development Study. London:

National Children's Bureau, City University, Economic and Social Research Council.

Fogelman, K. (1983). Growing up in Great Britain: Collected papers from the National Child Development Study. London: Macmillan. 
Herrnstein, R. J., \& Murray, C. (1994). The bell curve: Intelligence and class structure in American life. New York: Free Press.

Horn, J. L., Loehlin, J. C., \& Willerman, L. (1979). Intellectual resemblance among adoptive and biological relatives: The Texas adoption project. Behavior Genetics, 9, 177-207.

Hunter, J. E., \& Hunter, R. F. (1984). Validity and utility of alternative predictors of job performance. Psychological Bulletin, 96, 72-98.

Jencks, C. (1972). Inequality: A reassessment of the effect of family and schooling in America. New York: Basic Books.

Leask, S. J., \& Crow, T. J. (2001). Word acquisition reflects lateralization of hand skill. Trends in Cognitive Sciences, 5, 513-516.

Leete, R., \& Fox, J. (1977). Registrar General's social classes: Origins and uses. Population Trends, $8,1-7$.

Mackintosh, N. J. (1998). IQ and buman intelligence. Oxford: Oxford University Press.

Mascie-Taylor, C. G. N. (1984). Biosocial correlates of IQ. In C. J. Turner \& H. J. Miles (Eds.), The biology of human intelligence (pp. 99-127). London: Proceedings of the Eugenics Society.

Mascie-Taylor, C. G. N., \& Gibson, J. B. (1978). Social mobility and IQ components. Journal of Biosocial Science, 10, 263-276.

McCall, R. B. (1977). Childhood IQs as predictors of adult educational and occupational status. Science, 197, 482-3.

Murnane, R. J., Willett, J. B., \& Levy, F. (1995). The growing importance of cognitive skills in wage determination. Review of Economics and Statistics, 77, 251-266.

Nettle, D. (2002). Height and reproductive success in a cohort of British men. Human Nature, 13, 473-491.

OPCS (1980). Classification of occupations 1980. London: HMSO.

Robbins, L. (1963). Higher education: Report of the committee appointed by the prime minister under the chairmanship of Lord Robbins, 1961-3. London: HMSO.

Scarr, S., \& Weinberg, R. A. (1977). Intellectual similarities within families of both adopted and biological children. Intelligence, 1, 170-191.

Schmidt, F. L., \& Ones, D. S. (1992). Personnel selection. Annual Review of Psychology, 43, 627-670.

Steele, C. M., \& Aronson, J. (1995). Stereotype threat and the intellectual test performance of African Americans. Journal of Personality and Social Psychology, 69, 797-811.

Tittle, C. R., \& Rotolo, T. (2000). IQ and stratification: An empirical evaluation of Herrnstein and Murray's social change argument. Social Forces, 79, 1-28.

Waller, J. H. (1971). Achievement and social mobility: Relationships amongst IQ score, education and occupation in two generations. Social Biology, 18, 252-259.

Received I 7 May 2002; revised version received I 7 February 2003 